\title{
Somatostatin analogue SMS 201-995 long term therapy for
} vipoma

\author{
L.D. Juby, D.A. Burke and A.T.R. Axon \\ Gastroenterology Unit, The General Infirmary, Leeds LS1 3EX, UK.
}

\begin{abstract}
Summary: The definitive treatment of a pancreatic tumour secreting vasoactive intestinal polypeptide is surgical removal of the tumour, but when curative resection is not possible symptomatic treatment of the endocrine hyperfunction is important. Streptozotocin, although effective for palliation, can involve unpleasant side effects. We report the long term use of subcutaneous somatostatin analogue SMS 201-995 in an elderly man presenting with severe watery diarrhoea and anaemia due to a pancreatic vipoma. Good symptomatic improvement has been achieved with no side effects over a period of 24 months. We suggest there is a use for subcutaneous SMS 201-995 in elderly patients with inoperable pancreatic gut hormone producing tumours with metastases and in those where surgery would carry a high operative risk.
\end{abstract}

\section{Introduction}

The clinical picture of a pancreatic tumour secreting vasoactive intestinal peptide (vipoma) is dominated by diarrhoea, and associated with hypokalaemia, hypochlorhydria, and alkalosis. ${ }^{1}$ An excess of vasoactive intestinal peptide (VIP) stimulates water secretion in the intestine and pancreas leading to a secretory diarrhoea which may be life threatening. The definitive treatment for a vipoma is surgical removal, but presentation may occur after the tumour has metastasized or when major surgery is contraindicated by the patient's general condition. Symptomatic treatment can be achieved with streptozotocin but this may have unpleasant side effects. ${ }^{2}$ We describe an elderly patient with a pancreatic vipoma who has been treated symptomatically with a somatostatin analogue for 24 months.

\section{Case report}

In May 1984 a 79 year old retired salesman was referred with a seven month history of profuse, dark, watery, explosive diarrhoea, and burning sensation in the rectum on defaecation. Despite a good appetite he had lost 2 stones in weight. On examination he was clinically anaemic and had obvious weight loss. There were signs of congestive heart failure. Abdominal

Correspondence: L.D. Juby, M.B., Ch.B., M.R.C.P.

Accepted: 21 October 1986 examination revealed an ill-defined, irregular, nontender mass in the epigastrium.

Initial investigations revealed a hypokalaemic alkalosis (potassium $3.2 \mathrm{mmol} / 1$, bicarbonate $30 \mathrm{mmol} / \mathrm{l}$ ) with normal urea and liver function tests. The haemoglobin was $4.2 \mathrm{~g} / \mathrm{dl}$ with an iron deficiency picture. He was carefully transfused with 4 units of blood and the signs of cardiac failure resolved.

Barium studies demonstrated a mass displacing the duodenum. Abdominal ultrasound showed this to be a large mass causing separation of the aorta and inferior vena cava arising from the uncinate process of the pancreas. There were no hepatic metastases. Endoscopic retrograde cholangiopancreatography (ERCP) showed a mass in the head of the pancreas with compression of the pancreatic duct. A small gastric ulcer was seen high on the lesser curve with an ulcer in the second part of the duodenum; biopsies of the latter revealed an eroding pancreatic tumour with atypical cells consistent with a vipoma. Measurement of the stool output and electrolyte content showed him to have a secretory diarrhoea: on a normal diet the stools weighed $415 \mathrm{~g}$ with a 24 hour electrolyte content of sodium $15 \mathrm{mmol}$, potassium $40 \mathrm{mmol}$ (see Figure 1 period A) and on intravenous fluids with nil orally weighed $2800 \mathrm{~g}$ with 24 hour electrolyte content of sodium 339, potassium $51 \mathrm{mmol}$ (period B). Even though the stool output was low on a normal diet for a patient with secretory diarrhoea the stool was watery, the increased stool output on intravenous fluids was a better reflection of his normal stool output. A gut 


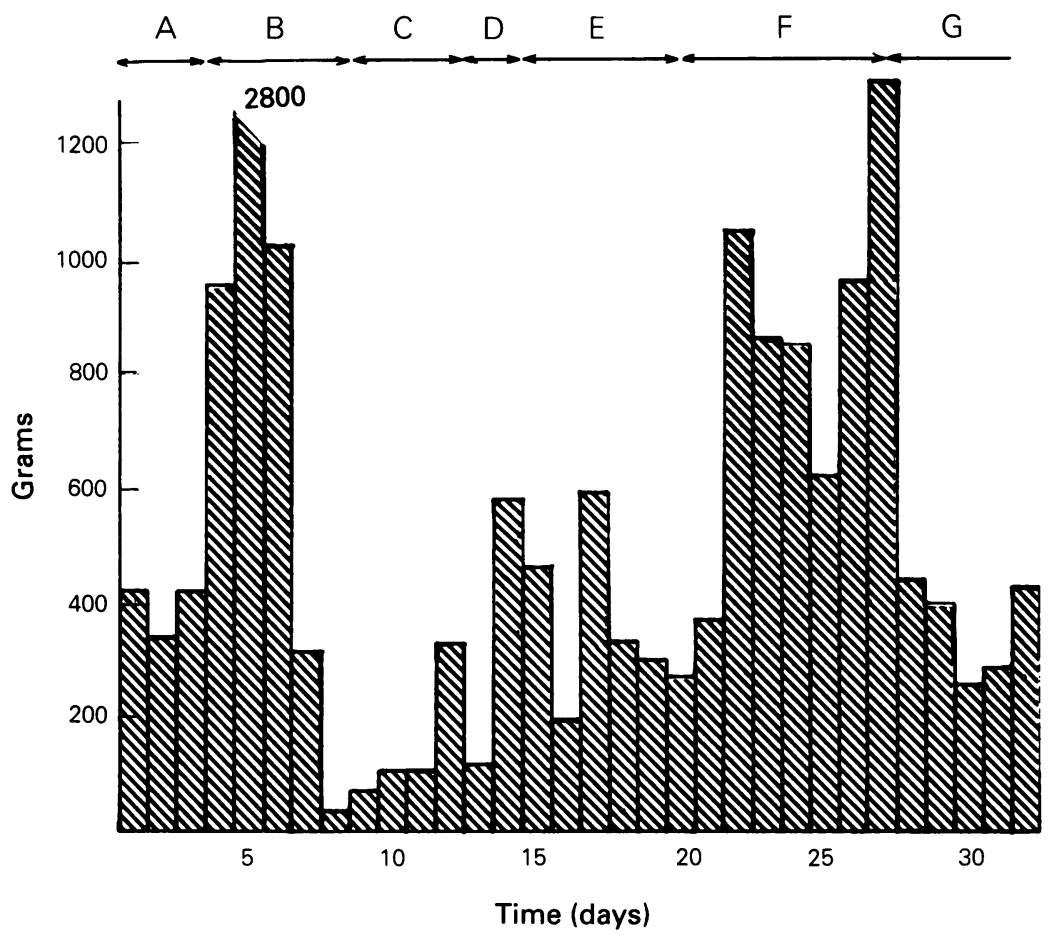

Figure 1 Graph showing stool weight $v$. days. A: Normal diet; B: intravenous fluids - nil by mouth; C: intravenous SMS 201-995 - nil by mouth; D: subcutaneous SMS 201-995 0600 h, 1800 h; E: subcutaneous SMS 201-995 0900 h, 2100 h; F: SMS 201-995 stopped/normal diet; G: subcutaneous SMS 201-995 0900 h, 2100 h.

hormone profile showed a raised VIP of $134 \mathrm{pmol} / 1$ (normal $<30 \mathrm{pmol} / \mathrm{l}$ ) and pancreatic polypeptide of $1000 \mathrm{pmol} / 1$ (normal $<300 \mathrm{pmol} / \mathrm{l}$ ).

He was given a trial of intravenous somatostatin analogue SMS 201-995 $25 \mu \mathrm{g} / \mathrm{h}$ for 4 days (period C) to elucidate whether he was responsive, followed by subcutaneous SMS 201-995 50 $\mu$ g twice daily with a normal diet for 7 days (see Figure 1); period D $0600 \mathrm{~h}$ and $1800 \mathrm{~h}$, period $\mathrm{E} 0900 \mathrm{~h}$ and $2100 \mathrm{~h}$ - this second period was suited to his meal times.

Subcutaneous SMS 201-995 resulted in symptomatic improvement and passage of a formed stool. $\mathrm{He}$ also noticed less colicky pain on defaecation. On stopping the SMS 201-995 there was a rebound effect with a recurrence of watery diarrhoea (period F), increased stool output compared to when on SMS 201-995, and general ill-health. In view of the good therapeutic response he was started on $50 \mu \mathrm{g}$ subcutaneous somatostatin SMS 201-995 twice daily (period G) with good effect and over 9 days learnt the injection technique, at which point we were able to discharge him home. Although there was little change in the stool weight, the stool became formed and he was asymptomatic. He has now been maintained on this regime for 24 months and his symptoms remain controlled. He has had no obvious side effects from? SMS 201-995 and he opens his bowels twice a day with no pain. Over this period he has had five admissions with melaena due to bleeding from the tumour as diagnosed endoscopically, but after bloofs transfusion has returned home each time after $72_{-}$. hours. A repeat ultrasound shows no increase in. tumour size and a gut hormone profile showed that the VIP concentration was lower.

\section{Discussion}

Somatostatin was first isolated from the hypoth alamus in $1972,{ }^{3}$ originally thought to be a specifiog hypothalamic factor modulating the release of growthn hormone, but now known to have a widespread actionN inhibiting secretion of growth hormone, thyrotrophin ${ }^{\omega}$ gastrin, gut hormones, insulin and glucagon. ${ }^{4}$ Raptis et al..$^{5}$ showed that somatostatin reduced plasma concentrations of gut hormones when infusedis intravenously. These findings suggested a therapeutic use for somatostatin in unresectable gut hormoneproducing tumours, but the major disadvantage wasid 
the short half-life of somatostatin of less than 3 minutes. ${ }^{6}$ Further work on somatostatin analogues with a longer half-life showed that gut hormone levels and stool volume could be reduced by administration both intravenously and subcutaneously. ${ }^{7-10}$ Long acting somatostatin analogues have now been used for the treatment of life-threatening diarrhoea ${ }^{9}$ and in one case caused shrinkage of the tumour. ${ }^{11}$ The mechanism of action is not known; flow studies demonstrate increased jejunal and ileal fluid absorption, increased potassium and chloride absorption and reversed sodium secretion, ${ }^{7}$ but these changes do not occur when somatostatin is given to healthy controls. ${ }^{12}$ It is unlikely that somatostatin acts entirely by direct stimulation of water and electrolyte absorption in the intestine, but more probably by either inhibition of tumour hormone release or by inhibition of the effect of tumour hormone on the intestinal mucosa.

\section{References}

1. Bloom, S.R. \& Polak, J.M. Vipomas and other tumours. In: Bouchier, I.A.D., Allan, R.N., Hodgson, H.F.J. \& Keighley, M.R.B. (eds) Textbook of Gastroenterology, 1st Edition. Bailliere Tindall, London, 1984, pp 13451350.

2. Moertel, C.G., Hanley, J.A., Johnson, L.A. Streptozocin alone compared with streptozocin plus fluorouracil in the treatment of advanced islet-cell carcinoma. $N$ Engl $J$ Med 1980, 303: 1189-1194.

3. Vale, W., Brazeau, P., Grant, G. et al. Premieres observations sur le mode d'action de la somatostatin, un facteur hypothalamique qui inhibe la secretion de l'hormone de croissance. C R Acad Sci Paris 1972, 275: 29132916.

4. Gerich, J.E. \& Patton, G.S. Somatostatin: physiology and clinical applications. Med Clin North Am 1978, 62: 375-392.

5. Raptis, S., Schlegel, W. \& Pfeiffer, E.F. Effects of somatostatin on gut and pancreas. In: Bloom, S.R. (ed) Gut Hormones, 1st Edition. Churchill Livingstone, Edinburgh, 1978, pp 446-452.

6. Long, R.G., Adrian, T.E., Brown, M.R. et al. Suppression of pancreatic endocrine tumour secretion by longacting somatostatin analogue. Lancet 1979, ii, 764-767.

7. Ruskone, A., Rene, E., Chayvialle, J.A. et al. Effect of somatostatin on diarrhoea and on small intestinal water and electrolyte transport in a patient with pancreatic cholera. Dig Dis Sci 1982, 27: 459-466.
The use of somatostatin analogue is now well recognized but there have been few reports on the use for long-term management. ${ }^{13,14}$ The patient we report leads an active life and is able to pursue hobbies, having no problems with incontinence. We have avoided major surgery and controlled his symptoms with no side effects. We therefore feel treatment with somatostatin analogue SMS 201-995 is useful in patients where surgery is contraindicated and side effects are encountered with streptozotocin and can be used in the long term with no deleterious effects.

\section{Acknowledgements}

We would like to thank Professor Bloom's laboratory at Hammersmith Hospital, London for their help with gut hormone estimations, and Sandoz Pharmaceuticals for supplying the SMS 201-995.

8. Adrian, T.E., Barnes, A.J., Long, R.G. et al. The effect of somatostatin analogs on secretion of growth, pancreatic, and gastrointestinal hormones in man. $J$ Clin Endocrinol Metab 1981, 53: 675-681.

9. Wood, S.M., Kraenzlin, M.E., Adrian, T.E. \& Bloom, S.R. Treatment of patients with pancreatic endocrine tumours using a long-acting somatostatin analogue symptomatic and peptide response. Gut 1985, 26: 438444.

10. Dharmsathaphorn, K., Sherwin, R.S. \& Cataland, S. Somatostatin inhibits diarrhea in the carcinoid syndrome. Ann Intern Med 1980, 92: 68-69.

11. Kraenzlin, M.E., Ching, J.C., Wood, S.M. \& Bloom, S.R. Can inhibition of hormone secretion be associated with endocrine tumour shrinkage? Lancet 1983, ii, 1501.

12. Guenter, J.K., Browne, R. \& Raskin, P. Effect of intravenous somatostatin on jejunal absorption of glucose, amino acids, water and electrolytes. Gastroenterology 1980, 78: 26-31.

13. Kraenzlin, M.E., Ching, J.L.C., Wood, S.M., Carr, D.H. \& Bloom, S.R. Long term treatment of a vipoma with somatostatin analogue resulting in remission of symptoms and possible shrinkage of metastases. Gastroenterology 1984, 88: 185-187.

14. Clements, D. \& Elias, E. Regression of metastatic vipoma with somatostatin analogue SMS 201-995. Lancet 1985, i, 874-875. 